\title{
Cloning of a rat-specific long PCP4/PEP19 isoform
}

\author{
ANNA SALA $^{1}$, MARIA SCATURRO ${ }^{2}$, PATRIZIA PROIA $^{3}$, GABRIELLA SCHIERA ${ }^{1}$, EPIFANIA BALISTRERI ${ }^{2}$, \\ REVITAL AFLALO-RATTENBACH ${ }^{4}$, NICOLE CRÉAU ${ }^{4}$ and ITALIA DI LIEGRO ${ }^{1}$ \\ ${ }^{1}$ Dipartimento di Scienze Biochimiche, ${ }^{2}$ Dipartimento di Biologia Cellulare e dello Sviluppo \\ 'Alberto Monroy', ${ }^{3}$ Dipartimento di Neurologia, Oftalmologia, Otorinolaringoiatria e Psichiatria, \\ University of Palermo, Palermo, Italy; ${ }^{4}$ EA3508, IFR117, University Denis Diderot, Paris, France
}

Received October 20, 2006; Accepted November 27, 2006

\begin{abstract}
We report the identification of a cDNA that encodes a putative protein of 94 amino acids and expected molecular weight of $10.7 \mathrm{kDa}$, the C-terminal half of which is identical to that of PEP19, a small, brain-specific protein involved in $\mathrm{Ca}^{++} /$calmodulin signaling. The novel rat-specific protein, tentatively named long PEP19 isoform (LPI), is the product of alternative splicing of the rat PCP4 gene encoding PEP19. We found that antibodies raised against the first $13 \mathrm{~N}$-terminal amino acids of LPI, not present in PEP19, recognize a protein enriched in the developing rat brain.
\end{abstract}

\section{Introduction}

Calcium is a highly versatile second messenger that regulates several cell functions (1). Most calcium-dependent signals rely on calmodulin $(\mathrm{CaM})$, a highly conserved protein that forms with calcium a complex able to induce activation of many target proteins, among which are kinases, phosphatases and proteases (2-4). In spite of CaM sequence conservation, $\mathrm{Ca}^{2+} /$ CaM-binding sites in target proteins exhibit low homology (5). Moreover, proteins that interact with $\mathrm{CaM}$ in a $\mathrm{Ca}^{2+}$ independent manner do also exist (6-8). Calcium and calmodulin have a critical role in nerve cell physiology. At the same time, uncontrolled increases in intracellular calcium can induce excitotoxicity and neuronal death $(9,10)$. Therefore, much attention has been focused on mechanisms that limit the concentration of active calmodulin in neurons (11). These studies led to the discovery of a family of neuron-specific peptides that contained an IQ motif similar to the one present in conventional myosins and involved in light chain binding (5). The best characterized examples of such peptides are neuro-modulin (12-15), neurogranin $(7,16,17)$ and PEP19 $(11,18)$. These peptides have been shown to bind calciumfree calmodulin and to inhibit $\mathrm{Ca}^{2+}$-calmodulin-dependent

Correspondence to: Professor Italia Di Liegro, Dipartimento di Scienze Biochimiche, Via del Vespro 129, 90127 Palermo, Italy

E-mail: diliegro@unipa.it

Key words: brain-specific proteins, neurons, PEP19, PCP4, LPI, IQ motifs, calmodulin nitric oxide synthase (NOS) in vitro (11). More recently, Johanson et al (19) have demonstrated that PEP19 can selectively modulate calcium-dependent activation of $\mathrm{CaM}$ kinase II in PC12 cells transfected so as to express physiological levels of PEP19. In addition, PEP19 has been suggested to play a role in neuroprotection $(11,20,21)$.

Herein, we describe a novel cDNA encoding a putative protein of 94 amino acids, the C-terminal half (41 amino acids) of which is identical to that of PEP19 and contains the IQ motif as well. The new protein is also transcribed by the PCP4 gene.

\section{Materials and methods}

Animals. Sprague-Dawley rats (Stefano Morini, San Polo d'Enza, Italy) were housed in our institutional animal care facility under direction of a licensed veterinarian. Procedures involving animals were conducted according to the European Community Council Directive 86/609, OJL 358 1, 12 December, 1987.

Cloning of putative $H 1^{\circ}$ RNA-binding proteins. Polyadenylated RNA from rat brain at postnatal day 10 (P10) was used as template for the synthesis of a cDNA population that was then cloned in the $\lambda$ gt11 Sfi-Not vector (Promega, USA). Screening of the library was done as described elsewhere (22). Briefly, the proteins produced by the clones were probed for their ability to bind ${ }^{32} \mathrm{P}$-radiolabeled $\mathrm{H} 1^{\circ}$ RNA, transcribed in vitro from the T3 RNA polymerase (Promega) promoter of the plasmid $\mathrm{pMH} 1^{\circ}$, which contains a rat $\mathrm{H} 1^{\circ}$ insert (EMBL accession number: X70685) (23). Positive inserts were subcloned into the bluescript plasmid vector and sequenced from both sides, using the Thermo sequenase radiolabeled terminator cycle sequencing kit (Amersham). Sequence analyses and alignments were done both by using MacMolly Tetra Programs, by Gene Soft, and by accessing nucleotide and protein sequence databases and tools, available on the web (http://www.ebi.ac.uk/Databases/; http://www.ncbi.nlm.nih. gov/; http://www.expasy.ch/).

Southern and Northern blot analyses. Human, mouse or rat genomic DNA (5-10 $\mu \mathrm{g})$ were digested with EcoRI restriction enzyme, separated by agarose gel electrophoresis and blotted onto Hybond $\mathrm{N}^{+}$membrane (Amersham Int.). Total RNA from developing or adult rat tissues was isolated (24), separated by 
electrophoresis on $1.5 \%$ agarose, $6 \%$ formaldehyde gels and transferred to nylon membranes (Hybond, Amersham). DNA blots were hybridized to the whole region encoding LPI (284 nt: from nt 81 to nt 365; probe 'a' of Fig. 1B). RNA blots were hybridized to ${ }^{32} \mathrm{P}$-labeled probes corresponding to either the LPI-specific region ( $\triangle \mathrm{LPI}, 126 \mathrm{nt}$ : from nt 111 to nt 237; probe ' $b$ ' of Fig. 1B) or to the sequence encoding the C-terminal half of LPI, common to PEP19 (C-end, $125 \mathrm{nt}$ : from nt 240 to nt 365; probe 'c' of Fig. 1B). The probes were obtained by polymerase chain reaction, using the following pairs of primers: probe 'a': 5'-dAGCGAATTCATGGAAA AGACAAGACATCAGGAG-3'; 5'-dCCCAAGCTTCTAG GACTGTGATCCTGCCTTTTT-3'. probe 'b' (LPI-specific): 5'-dAGCGAATTCGGCAAAGTGCTCACTGCCAGA GGAG-3'; 5'-dCCCAAGCTTTCAATATATTTCAGGAG CCTCCAG-3'. probe 'c' (C-end): 5'-dAGCGAATTCGGGC AGAAGAAGGTCCAAGAAGAA-3'; 5'-dCCCAAGCTT CTAGGACTGTGATCCTGCCTTTTT-3'. The 5'- and 3'primers included EcoRI and HindIII sites (underlined), respectively, to also allow oriented cloning of amplified fragments.

Preparation of tissue extracts and Western analysis. Fresh tissues from developing or adult rats were homogenized in homogenization buffer $(0.32 \mathrm{M}$ sucrose; $50 \mathrm{mM}$ sodium phosphate buffer, pH $6.5 ; 50 \mathrm{mM} \mathrm{KCl}, 0.5 \mathrm{mM}$ spermine; $0.15 \mathrm{mM}$ spermidine; $2 \mathrm{mM}$ EDTA, and $0.15 \mathrm{mM}$ EGTA), containing the protease inhibitors aprotinin $(2 \mu \mathrm{g} / \mathrm{ml})$, antipain $(2 \mu \mathrm{g} / \mathrm{ml})$, leupeptin $(2 \mu \mathrm{g} / \mathrm{ml})$, pepstatin $\mathrm{A}(2 \mu \mathrm{g} / \mathrm{ml})$, benzamidine $(1.0 \mathrm{mM})$, and phenylmethylsulfonyl fluoride $(1.0 \mathrm{mM})$, all purchased from Sigma. The homogenate was centrifuged at $1000 \mathrm{xg}$ for $10 \mathrm{~min}$ at $4^{\circ} \mathrm{C}$ and the supernatant (post-nuclear extract, PN) was immediately split into aliquots and rapidly frozen in liquid nitrogen. Nuclear salt extracts (Nex) were prepared according to Dignam et al (25). Protein concentration was determined according to Bradford (26). Total proteins (15-30 $\mu \mathrm{g}$ ) were separated by electrophoresis on denaturing $18 \%$ polyacrylamide slab gels (SDS-PAGE), and immunoblotted as described elsewhere (27). The blots were treated with one of the following antibodies: i) rabbit polyclonal anti-PEP19 antibodies (kind gift of Dr J.I. Morgan): these antibodies should recognize both PEP19 and LPI (28); ii) rabbit polyclonal anti-LPI/PEP19 antibodies, produced in our laboratory, as described elsewhere (29), using as antigen the entire recombinant LPI (rLPI), containing an N-terminal tag of six histidines (see below); these antibodies should recognize both PEP19 and LPI and are indicated as antiLPI/PEP19 antibodies throughout the study; iii) LPI-specific antibodies, raised against a synthetic peptide corresponding to the first $13 \mathrm{~N}$-terminal amino acids (MEKTRHQEIMAKC) of putative LPI (Igtech, Perdifumo, Italy); these antibodies should not recognize PEP19 and will be indicated as 'antiLPI N-end' throughout the study.

Cloning of PEP19 cDNA. From a mix ( 1 mg) of total RNA containing equal amounts of RNA from five developmental stages (P1, P5, P10, P20 and P30), polyadenylated RNA was purified with the PolyATract ${ }^{R}$ mRNA Isolation System IV kit (Promega), according to the manufacturer's instructions. Polyadenylated RNA was then used as a template for reverse
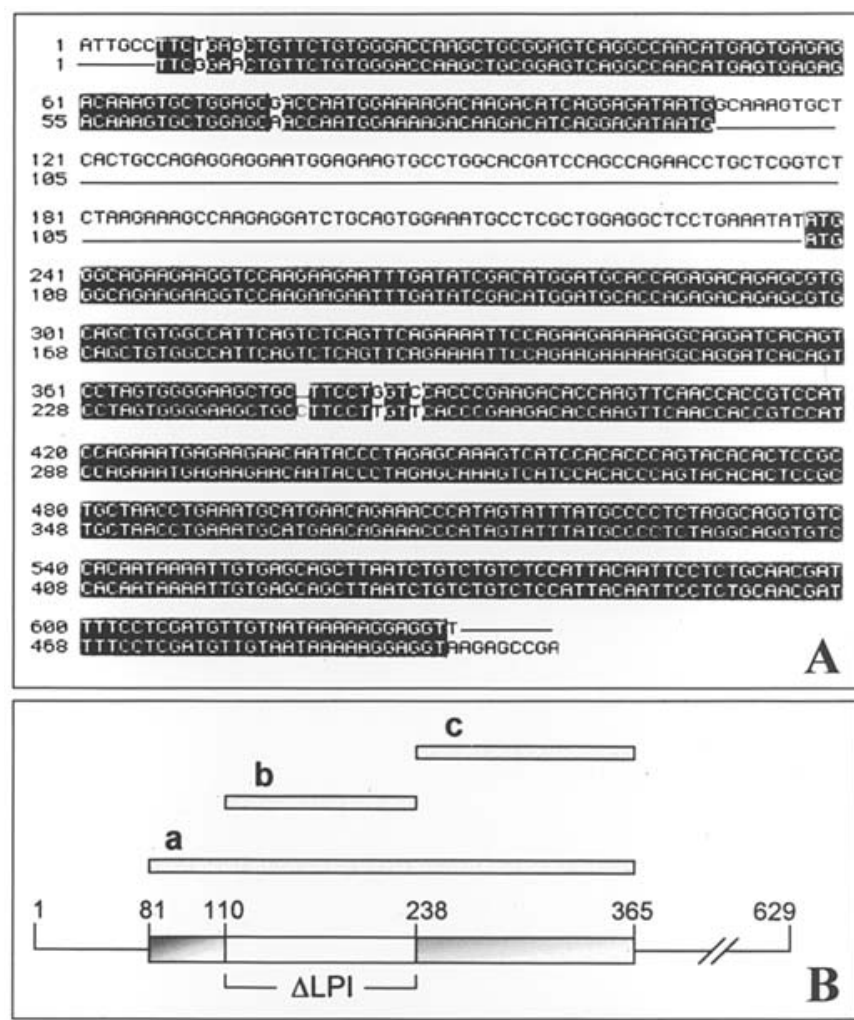

Figure 1. LPI-encoding cDNA. A, alignment of LPI-encoding cDNA (upper sequence; EMBL accession number: AJ_493658) with PEP19/PCP4 cDNA sequence (lower sequence; EMBL accession number: NM_013002). Identical nucleotides are included in black boxes. B, a schematic drawing of LPI cDNA; numbers refer to the cDNA nucleotide sequence; positions corresponding to the LPI-specific region are marked as $\Delta$ LPI. Positions of the probes a, b, and c, used in the hybridization analyses are schematically indicated.

transcription and amplification reaction (RT-PCR), by using the AccessQuick ${ }^{\text {TM }}$ RT-PCR system kit (Promega) and the following pair of primers: 5'-CTGTTCTGTGGGACCAA GCTGCGGAGTCAG (5'-primer); 5'-TTTTTTTTTTTTT TTTTTTTTTTTTTTTTT (3'-primer).

The product of this reaction was the template of a further PCR reaction that made use of a second pair of primers: 5'-A GTGAATTCGGGACCAAGCTGCGGAGTCAGGCC (5'primer); 5'-CCCGGATCCAACATCGAGGAAAATCG TTGCAGA (3'-primer).

The second pair of 5'- and 3'-primers included EcoRI and BamHI sites (underlined), respectively, to allow oriented cloning of the amplified fragment into the bluescript plasmid vector (pBS $\mathrm{KS}^{+}$, Clontech). After cloning, the insert was sequenced from both sides and was found to be identical to the sequence registered with the EMBL accession number: NM_013002.

Preparation of recombinant PEP19 (rPEP) and recombinant LPI (rLPI) containing N-terminal tags of six histidines. To synthesize recombinant PEP19, the entire coding region of PEP19 cDNA was amplified, by polymerase chain reaction, using the following attB-modified custom primers (Invitrogen): 5'-dGGGGACAAGTTTGTACAAAAAAGCAGGCT TAATGAGTGAGAGACAAAGTGCTGGAGC-3'; 5'-d 
Table I. Intron-exon junctions in human, mouse and rat PCP4 genes.

\begin{tabular}{|c|c|c|c|c|c|}
\hline Species & Exons & 5'-splice donor & $\begin{array}{c}\text { NNSPLICE } \\
\text { score }\end{array}$ & 3'-splice acceptor & $\begin{array}{c}\text { NNSPLICE } \\
\text { score }\end{array}$ \\
\hline \multirow[t]{3}{*}{ Human } & Exon 1 & TGAGTGAG/gtgagtgatg & 0.99 & & \\
\hline & Exon 2 & TGAAAATG/gtaagaggac & 0.99 & ttttttgcctttag/CGACAAGGT & 0.94 \\
\hline & Exon 3 & & & ttgtcttgctacag/ATGGACAGAA & 0.89 \\
\hline \multirow[t]{3}{*}{ Mouse } & Exon 1 & CAACATGA/gtgaggtgag & 0.98 & & \\
\hline & Exon 2 & AGATAATG/gtaagatgac & 0.99 & taaaatgtttatag/AGACAAAGTG & 0.66 \\
\hline & Exon 3 & & & gttttttactacag/ATGGGCAGAA & 0.98 \\
\hline \multirow[t]{3}{*}{ Rat } & Exon 1 & TGAGTGAG/gtaagcaatc & 0.93 & & \\
\hline & Exon 2 & AGATAATG/gtaagatggt & 0.99 & taaaatgttttcag/AGACAAAGTG & 0.55 \\
\hline & Exon 3 & & & tgtttttgctacag/ATGGGCAGAA & 0.99 \\
\hline \multirow{4}{*}{$\begin{array}{l}\text { Rat long } \\
\text { isoform }\end{array}$} & Exon 1 & TGAGTGAG/gtaagcaatc & 0.93 & & \\
\hline & Exon 2 & AGATAATG/gtaagatggt & 0.99 & taaaatgttttcag/AGACAAAGTG & 0.55 \\
\hline & Exon 3 & TGAAATAT/gtaggggtcc & 0.01 & tcacacggccacag/GCAAAGTGCT & - \\
\hline & Exon $3^{*}$ & & & tgtttttgctacag/ATGGGCAGAA & 0.99 \\
\hline
\end{tabular}

Exon sequences are in capital, intron sequences are in lower case letters.

GGGGACCACTTTGTACAAGAAAGCTGGGTCGGA CTGTGATCCTGCCTTTTTCTT-3'.

To synthesize recombinant LPI, the entire putative coding region of LPI insert (EMBL accession number: AJ_493658) was amplified, by polymerase chain reaction, using the following attB-modified custom primers (Invitrogen): 5'-d GGGGACAAGTTTGTACAAAAAAGCAGGCTTAGAAA AGACAAGACATCAGGAGATA-3'; 5'-dGGGGACCAC TTTGTACAAGAAAGCTGGGTCGGACTGTGATCCTG CCTTTTTCTT-3'.

In both cases, the 5'- and 3'-primers included attB1 and attB2 recombination sequences (underlined) for cloning the amplification products sequentially into the pDONR201 plasmid vector and into the $\mathrm{pDEST}^{\mathrm{TM}}-17$ plasmid expression vector (Gateway ${ }^{\mathrm{TM}}$ Technology, Invitrogen), according to Gateway Technology (Invitrogen), that is based on the sitespecific recombination reactions of bacteriophage $\lambda$ in $E$. coli. The expression clones pDEST-17 were finally transferred into $E$. coli BL21-SI competent cells to obtain expression of the N-terminal histidine fusions with PEP19 and LPI, respectively.

Chromatographic purification of recombinant proteins and preparation of rabbit anti-LPI serum. Recombinant proteins were purified from bacterial homogenate by metal-affinity chromatography on a selective nickel-nitriloacetic (Ni-NTA)conjugated agarose matrix (QIAexpress System, Qiagen), according to the manufacturer's instructions. Bound proteins were eluted with $250 \mathrm{mM}$ imidazole and dialyzed against distilled water. Recombinant LPI was used to immunize two different rabbits, as described elsewhere (29).

In silico analysis. cDNA and genomic sequences were compared using BLAST (30), BLAST2 (31) and CLUSTALW
(32) programs at NCBI (http://www.ncbi.nlm.nih.gov/) or EBI (http://www.ebi.ac.uk/) sites. Genomic sequences from PCP4 intron2 were extracted from NCBI databases. Sequences of reference for rat PCP4 gene (RNO11) is NC_005110 (RGSC v3.4 June 2006), for mouse PCP4 gene (MMU16) strain C57Bl/6 is NC_000082 and strain 129 is AC023613 (PAC RP21-546K22), for the human PCP4 gene (HSA21) is NC_000021. Statistical analysis of potential splice sites for the PCP4 exons were performed at http://www fruitfly.org/ seq_tools/splice.html (33).

Statistical analysis. A minimum of 3 independent autoradiographs (for Northern analyses) or immunostained membranes (for Western blots) were scanned and planimetries of scans were used to calculate, by the Image J program, average concentrations of PEP19/LPI mRNA and proteins at different stages of brain development; values were normalized with respect to the total amount of rRNA in the lane (Northern analyses), or the total amount of proteins visualized by Ponceau Red staining (Western blots). The results of these analyses were used to calculate mean relative values and SD for each age studied.

\section{Results}

Isolation of a cDNA encoding a putative RNA-binding protein. One possible way to identify RNA-binding proteins is to screen expression libraries with ${ }^{32} \mathrm{P}$-labeled RNA of interest. In looking for $\mathrm{H}^{\circ}$ mRNA-binding factors through this approach, we isolated a cDNA of 629 nucleotides (nt), the sequence of which is identical, for most of its length, to the one encoding the brain-specific peptide known as PEP19 transcribed from the PCP4 gene. Therefore, we called its putative translational product long PEP19 isoform (LPI). The novel 


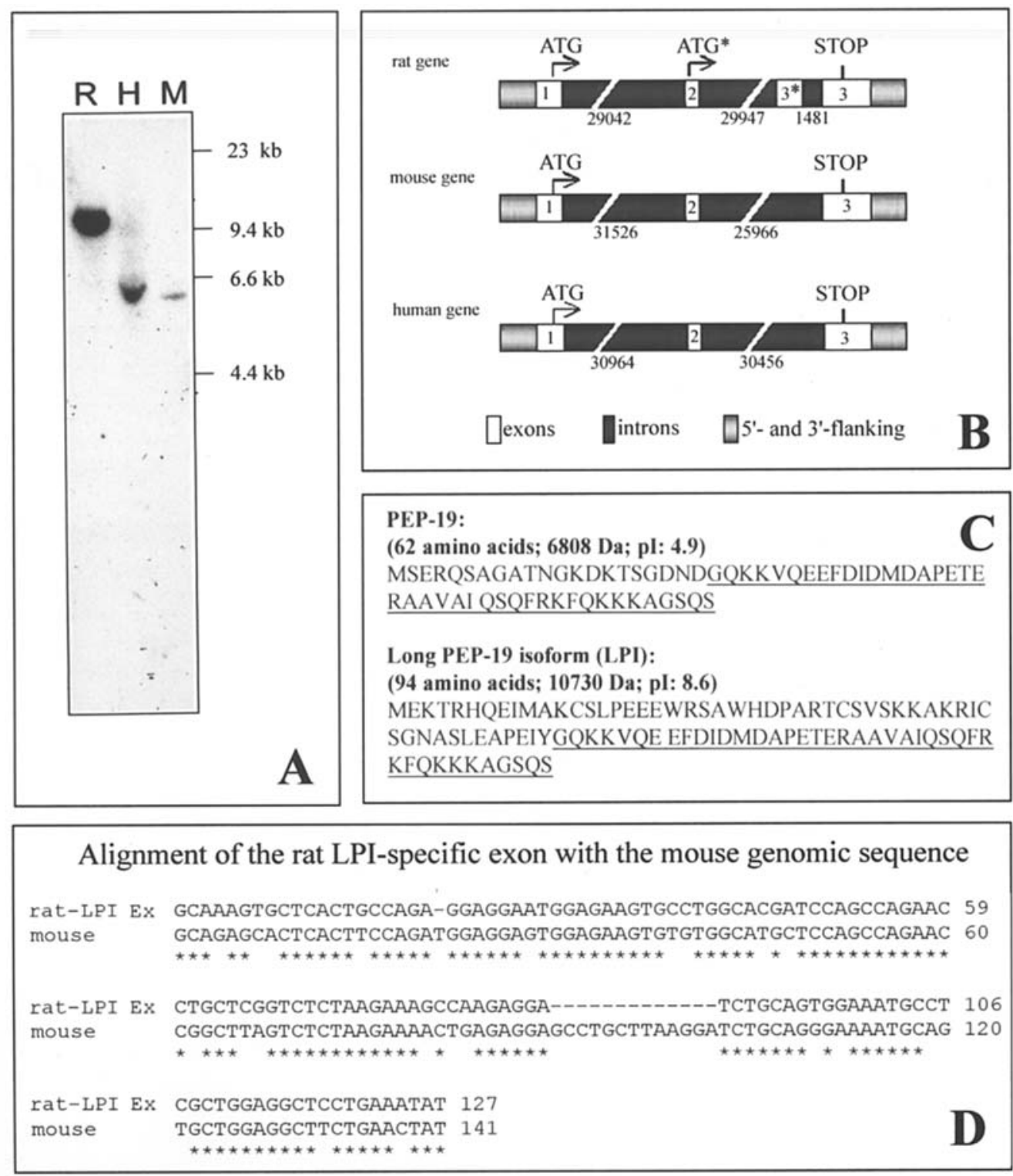

Figure 2. Southern analysis and genomic organisation of the PCP4 (PEP19) genes in rat, mouse and human. A, genomic DNA from rat (R), human (H) or mouse (M), digested with EcoRI restriction enzyme, was hybridized to probe a of Fig. 1B. B, schematic drawing of PCP4 genes; the representation of exons and introns is not to scale. The size in bp of the introns are indicated at the bottom. For the rat gene, the LPI-specific exon is named $3^{*}$. Note that in the LPI form $\left(\mathrm{ex} 1+\mathrm{ex} 2+\mathrm{ex} 3^{*}+\mathrm{ex} 3\right)$ the start site for translation $\left(\mathrm{ATG}^{*}\right)$ is different, but the stop codon is the same as in the short form (ex $\left.1+\mathrm{ex} 2+\mathrm{ex} 3\right)$. The complete amino acid sequences of the corresponding peptides are reported in $\mathrm{C}$, where expected molecular masses and isoelectric points (pI) are also shown. Amino acids, present in the C-terminal halves of both molecules are underlined. D, alignment of the rat LPI-exon and the mouse genomic sequence. The sequence found in mouse chromosome 16 to be homologous to the rat LPI-exon was aligned using CLUSTALW (31). Note the insertion of 13 bp in the mouse sequence.

cDNA (Fig. 1A: upper sequence; EMBL accession number: AJ_493658) contains an internal sequence of 127 nucleotides (from nt 111 to nt 237; indicated as $\Delta$ LPI throughout this study, Fig. 1B) that is not present in the PEP19-encoding cDNA (Fig. 1A: lower sequence; EMBL accession number: NM_013002).

Comparison of rat, mouse and human PCP4 genes encoding PEP19 and LPI. Fig. 2A shows the results of Southern analysis indicating that only one gene, recognized by the entire coding region of the insert (probe ' $a$ ' of Fig. 1B), is present in the rat genome. This gene, PCP4, is conserved among rat, mouse and human, and is localized on rat chromosome 11, murine chromosome 16 and human chromosome 21. When rat LPI
cDNA was aligned to rat, mouse and human genomic sequences (BLASTN), we found that a putative fourth exon (indicated as $3^{*}$ in Fig. 2B), corresponding to the additional nucleotides of the LPI cDNA (AJ_493658), is present only in the rat genome, while PEP19 mRNA is encoded by the same 3 exons in all the three species. Homologies between rat and mouse exons were: exon 1,98\% over the last 58 bp; exon 2 , $94 \%$ over the $52 \mathrm{bp}$, and exon 3, $93 \%$ over $378 \mathrm{bp}$. Homologies between rat and human exons were lower: $78 \%$ for exon 1 , $92 \%$ for exon 2 , and $86 \%$ for exon 3 . In the rat genome, the additional exon $\left(3^{*}\right)$ is closer (1481 bp) to exon 3 than to exon 2.

Translation of the two putative overlapping mRNAs, corresponding to LPI-cDNA (Fig. 1A, upper sequence) and 
B T K S L Lu Mu
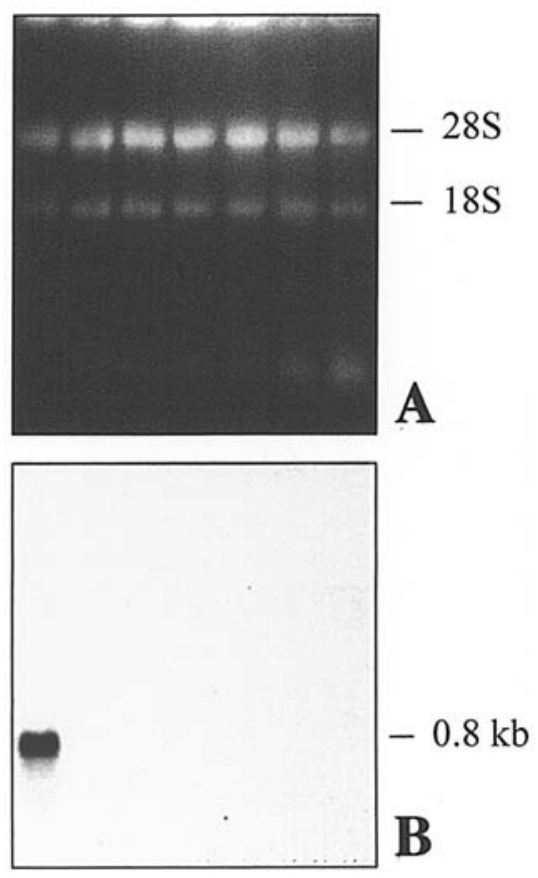

Figure 3. Northern blot analysis of total cellular RNA from different rat tissues, hybridized to LPI-specific probe. Total RNA from brain (B), testis $(\mathrm{T})$, kidney $(\mathrm{K})$, spleen $(\mathrm{S})$, liver $(\mathrm{L})$, lung $(\mathrm{Lu})$ and muscle $(\mathrm{Mu})$ of adult rats was hybridized to the LPI-specific probe ' $b$ ' of Figure 1B. A, ethidium bromide staining; B, autoradiography. Approximate size of the transcript is reported on the right.
PEP19 cDNA (Fig. 1A, lower sequence), respectively, should give rise to two polypeptides with identical C-terminal halves, but different $\mathrm{N}$-terminal halves (Fig. 2C). The two proteins should have both different expected molecular masses $(\sim 10 \mathrm{kDa}$ in the case of putative LPI and $\sim 7 \mathrm{kDa}$ in the case of PEP19) and different isoelectric points, with LPI showing a basic one (pI, 8.6).

The 127 bp-long 'LPI-exon' showed only 83\% homology with mouse chromosome 16 (Fig. 2D). The potential exon in the mouse has stop codons in all the frames, suggesting that an LPI-like protein (94 aa) cannot exist in this species. No homology with the LPI-exon could be found within the human genomic sequence.

The intron-exon junctions were determined using in silico analysis. Table I shows the junctions for the three species and the score found using the program NNPSPLICE (33). The scores are higher for the human sequence and LPI-exon junctions were not found by this program. The intronic junction sequences for the LPI-exon showed 85-90\% homology with the mouse sequences.

Tissue-specificity of LPI-specific messengers. According to the genomic analysis, LPI mRNA should be specific of rat, where it should derive from alternative splicing of the same primary transcript encoding PEP19 (Fig. 2). PEP19 was first described in the rat by Ziai et al (18) as a brain-specific peptide of $7.6 \mathrm{kDa}$. To ascertain whether the additional insert, present in LPI cDNA, is also present in brain-specific transcripts, we
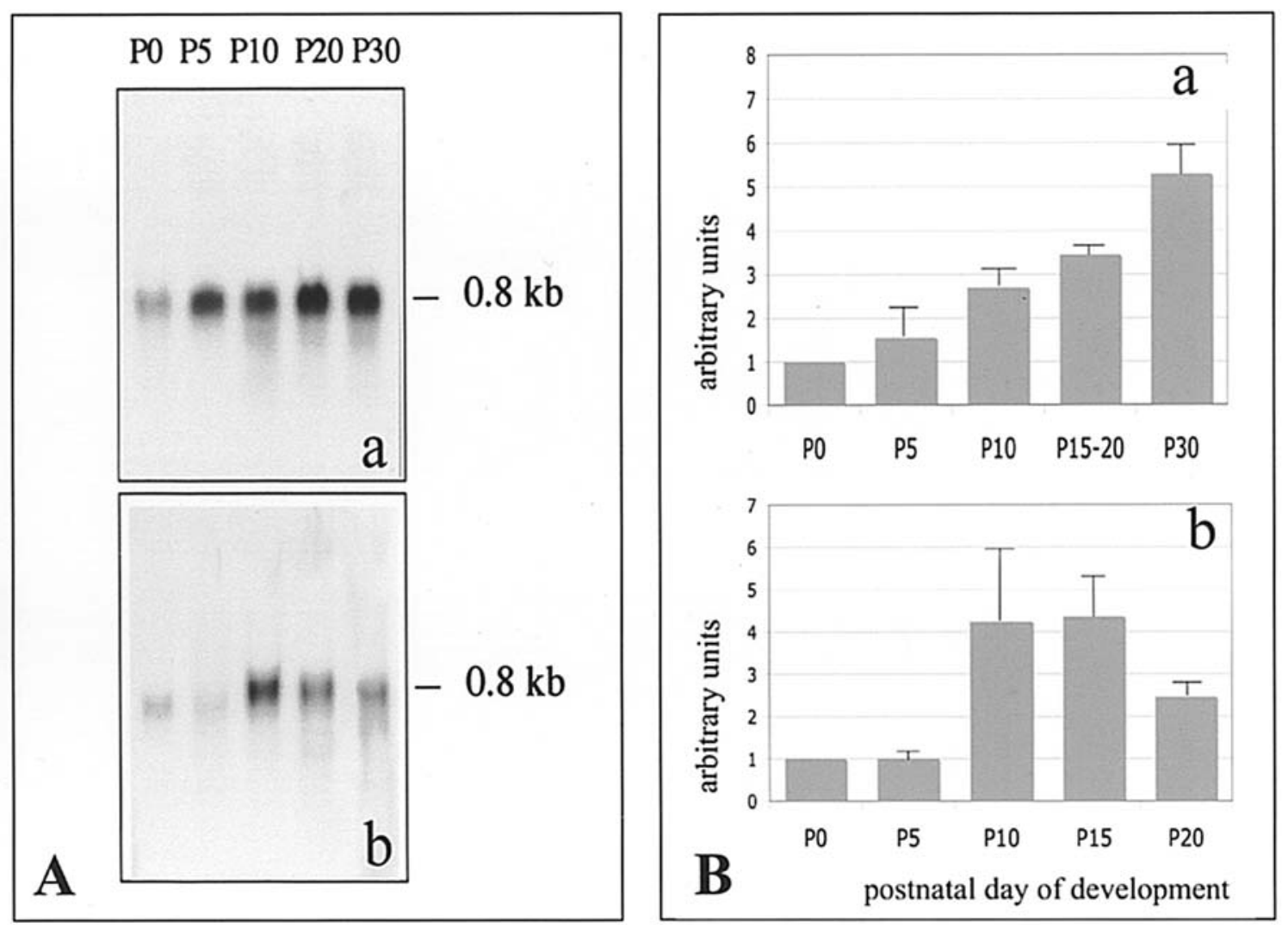

Figure 4. Northern blot analysis of total cellular RNA from rat brains at different ages of development. (A) Total RNA from rat brains at different postnatal (P) days of development was hybridized to either probe 'c' (a) or probe 'b' (b) of Fig. 1B. Approximate size of the transcript is reported on the right margin; (B) Four independent Northern blots were scanned and analyzed with the ImageJ program. The results were used to calculate mean relative concentrations of (PEP19 + LPI) mRNA(Ba) or LPI-specific mRNA (Bb). Grey bars indicate mean values. SD is also reported. 

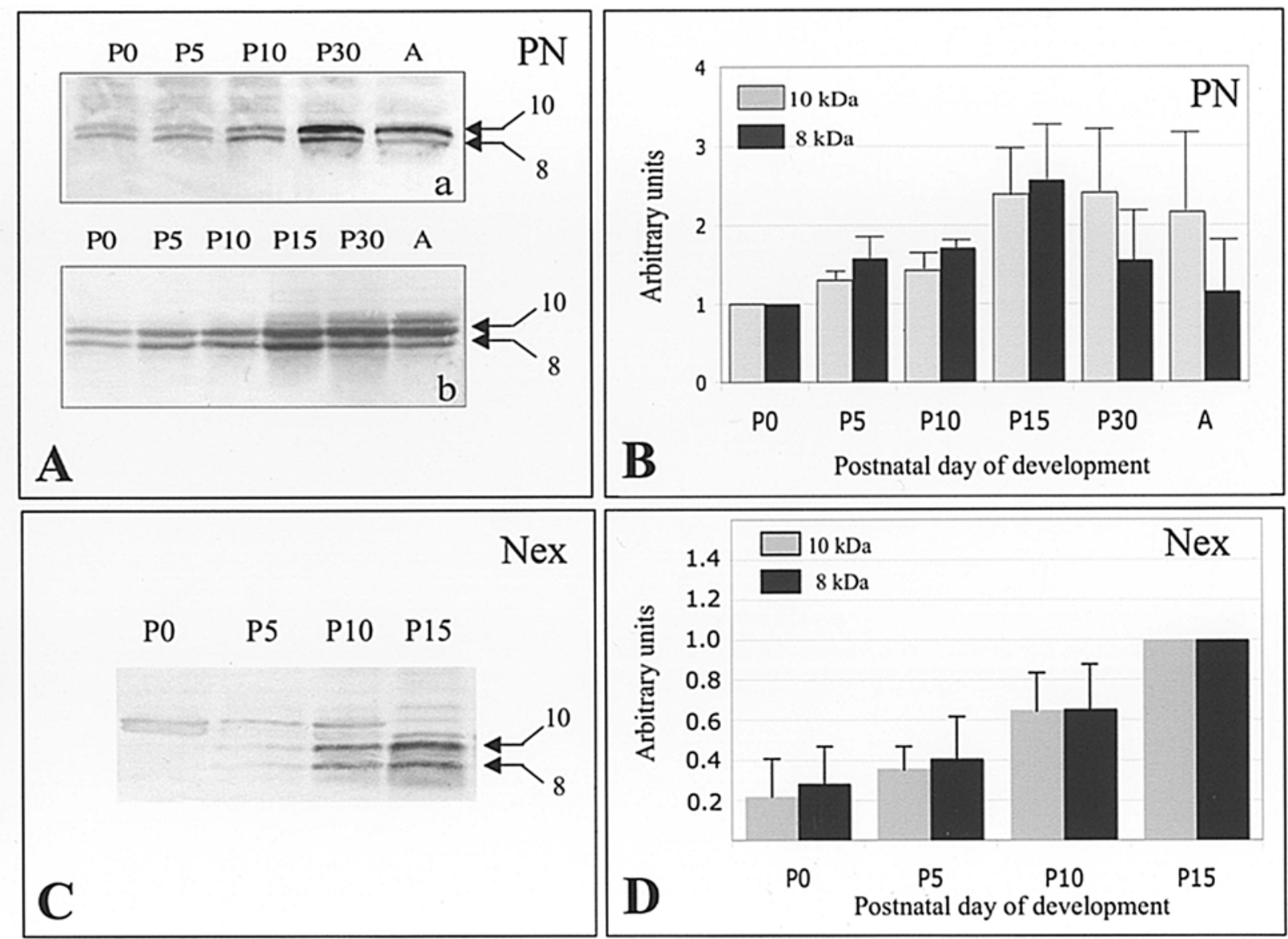

Figure 5. Different proteins, recognized by either anti-PEP19- or anti-LPI-antibodies, accumulate to different levels in the developing rat brain. Western blot of postnuclear- (A) or nuclear- (C) homogenates (20 $\mu \mathrm{g}$ each) from rat brains of different ages of development, immunostained with either rabbit polyclonal anti-PEP19-serum (Aa) or anti-LPI/PEP19 serum (Ab). Given the identity in their C-ends, both LPI and PEP19 were expected to be immunostained by both antibodies. At least three independent Western blots were scanned and analyzed with the ImageJ program. The results were used to calculate mean relative concentrations of the 10 - and the 8 -kDa proteins in both postnuclear- (PN; B) and nuclear- (Nex; D) extracts. Grey bars indicate mean values. SD is also reported. $\mathrm{P}$, postnatal day of development; A, adult rat.

hybrized total RNA prepared from different tissues of adult rat to the LPI-specific probe ' $b$ ' of Fig. 1B. This analysis revealed only one species of mRNA (Fig. 3), in the same range of size $(\sim 0.8 \mathrm{~kb})$ as previously reported for PEP19-encoding mRNA (34), and also brain-specific. Thus, two different transcripts should derive from the same primary PCP4 transcript by alternative splicing, and both should be brain-specific.

Developmental expression of LPI messengers. Fig. 4 shows the results of Northern analyses performed, in developing rat brain, with either probe 'c' (Fig. 4Aa), corresponding to the region that encodes the C-terminal common halves of the two peptides, or LPI-specific probe 'b' (Fig. 4Ab). Although a single species of $0.8 \mathrm{~kb}$ is visible in both cases, the developmental profiles obtained are different: the concentration of the total mRNA population recognized by probe 'c' (PEP19 + LPI) increases up to postnatal day 30 (P30; Fig. 4Ba), while LPI mRNA increases up to P15 but decreases afterwards (Fig. 4Bb).

Anti-LPI/PEP19 and 'anti-LPI N-end' antibodies react with peptides that show different developmental expression profiles. As mRNAs encoding LPI and PEP19 seemed to be differently represented at each developmental stage analyzed, we tested what happened with the encoded peptide(s). We used an anti-
PEP19 antibody directed against an amino acid sequence present in the C-terminal half of the molecule (28), and analyzed the expression of immunoreactive proteins in the post-nuclear cell fraction (Fig. 5Aa). Given the identity between LPI and PEP19 in the C-end (recognized by this antibody), we expected to immunostain both proteins. We observed two bands, of $\sim 10$ - and 8-kDa, respectively. We also found that the $10-\mathrm{kDa}$ band predominates over the $8-\mathrm{kDa}$ band after P10 and in the adult. The Western analyses were repeated by using the anti-serum raised against recombinant LPI (rLPI), prepared in our laboratory (Fig. 5Ab). Again, these antibodies are expected to recognize both proteins, as they were raised against the entire rLPI that includes the PEP19-shared $\mathrm{C}$-end. These antibodies indeed revealed in PN two bands that are also present in the nuclear salt extracts (Nex; Fig. 5C). At least three different Western blots like those shown in Fig. 5A and $\mathrm{C}$, were used to calculate the mean relative concentration of putative LPI and PEP19 polypeptides at different stages of postnatal development, in the postnuclear- (Fig. 5B) and the nuclear-fraction (Fig. 5D), respectively.

This first set of analyses suggested the existence of two PCP4 gene products: one ( $~ 8 \mathrm{kDa}$ in size) might correspond to PEP19, while the other ( $10 \mathrm{kDa})$ might correspond to LPI. In order to clarify the identity of the bands identified, we used a 


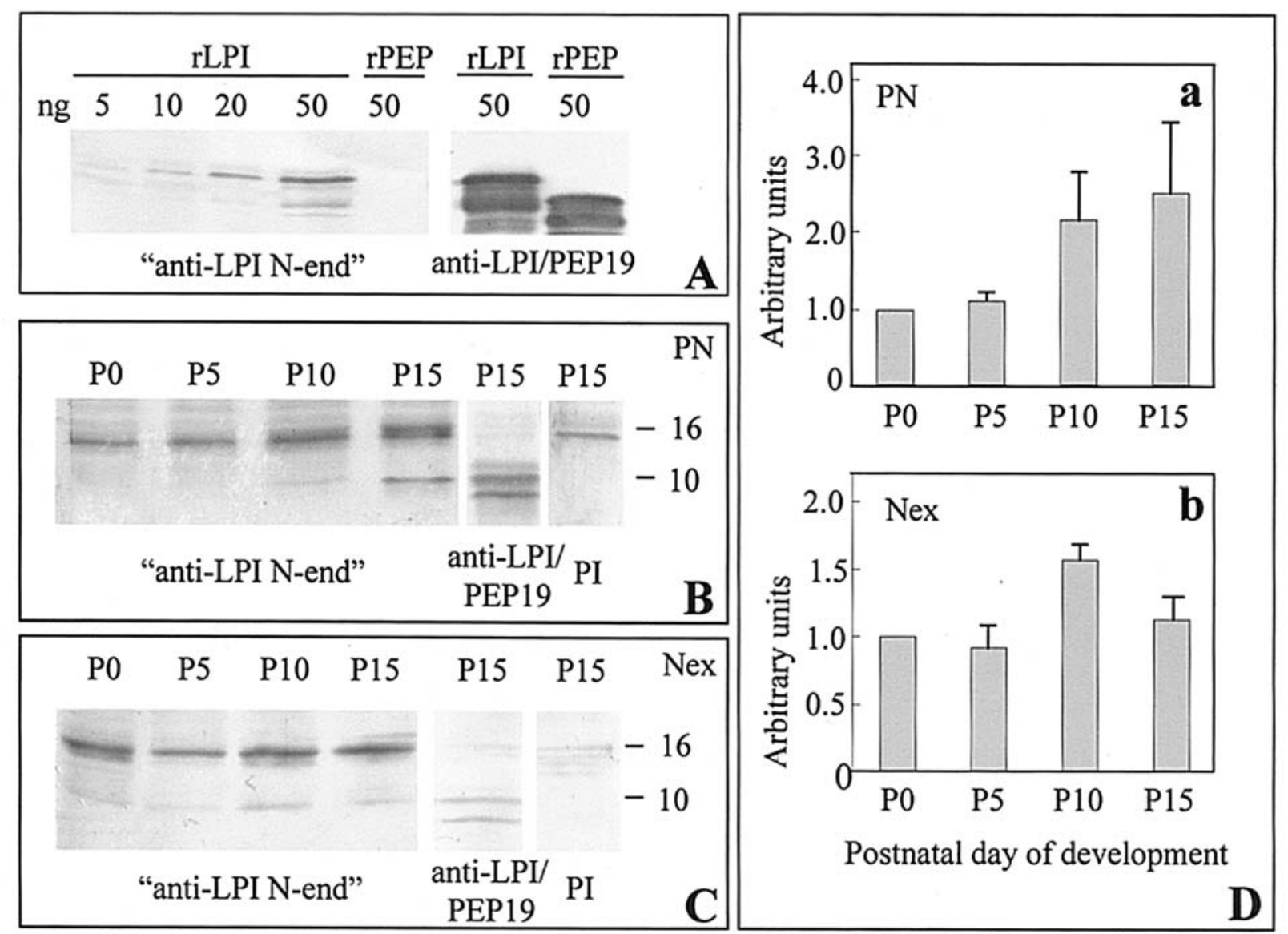

Figure 6. LPI-specific serum ('anti-LPI N-end' antibodies) recognizes a 10-kDa protein present both in the postnuclear- and nuclear-cell extracts. A, determination of the titer and specificity of the antibodies raised against the $13 \mathrm{~N}$-terminal amino acids of putative LPI ('anti-LPI N-end' serum). Different amounts $(5,10,20$, and $50 \mathrm{ng})$ of recombinant LPI (rLPI) were immunostained with 'anti-LPI N-end' antibodies, in parallel with 50 ng of recombinant PEP19 (rPEP), as negative control. As an internal control, both rLPI and rPEP (50 ng each) were also immunostained with the antibody that recognizes both proteins (anti-LPI/PEP19). B and C, Western blot of postnuclear- (B) and nuclear- (C) homogenates (20 $\mu \mathrm{g}$ each) from rat brains at different ages of development, immunostained with 'anti-LPI N-end' serum. As an internal control, identical amounts of P15 extracts were also immunostained with anti-LPI/PEP19 antibodies and with preimmune serum (PI) of the rabbit immunized with the 'LPI-Nend'. At least three independent Western blots were scanned and analyzed with the ImageJ program. The results were used to calculate mean relative concentrations of the $10 \mathrm{kDa}$ protein in both postnuclear- (PN; Da) and nuclear$(\mathrm{Nex} ; \mathrm{Db})$ extracts. Grey bars indicate mean values. SD is also indicated. P, postnatal day of development; A, adult rat.

third antibody, raised against the first $13 \mathrm{~N}$-terminal aminoacids (MEKTRHQEIMAKC), present only in the putative LPI. Titer and specificity of the new antibodies ('antiLPI N-end' serum) were tested by Western analysis on both recombinant PEP19 (rPEP) and recombinant LPI (rLPI); as shown in Fig. 6, 'anti-LPI N-end' antibodies recognize rLPI but not rPEP (Fig. 6A). Among cell proteins, 'anti-LPI N-end' antibodies recognized a protein of $10 \mathrm{kDa}$, both in the postnuclear- (Fig. 6B) and in the nuclear- (Fig. 6C) extracts, as we expected. The changes of LPI concentration in the first two weeks of brain development are very similar, independent of the antibodies used for studying them (compare Fig. 6Da and Db with Fig. 5B and D, respectively). However, in the adult rat, the $10-\mathrm{kDa}$ protein was scarcely visible, especially in the postnuclear extracts, when we used the 'antiLPI N-end' antiserum. Probably, the 10-kDa species previously evidenced with general anti-LPI/PEP19 antibodies is made up of at least two different proteins: LPI (produced earlier during brain development and less represented in the adult brain) and some post-translationally modified form of PEP19 itself (the main form present in the adult brain).
A further observation concerns the existence of a $16-\mathrm{kDa}$ band, recognized with high affinity by 'anti-LPI N-end' serum (Fig. 6). As a protein of approximately same size is also recognized by the preimmune serum (Fig. $6 \mathrm{~B}$ and $\mathrm{C}, \mathrm{PI}$ ), this band is likely to be the result of a non-specific reaction. However, the intensity of the $16-\mathrm{kDa}$ band is much higher with the immune serum than with the preimmune one, especially in the nuclear extract.

\section{Discussion}

In this study, we report identification and developmental pattern of expression of a new basic protein of $\sim 10 \mathrm{kDa}$, derived, by alternate splicing, from the same primary transcript encoded by the PCP4 gene that encodes the brain-specific peptide, of $\sim 8 \mathrm{kDa}$, known as PEP19/PCP4. The new protein, that we called long PEP19 isoform (LPI), is brain-specific as well, and probably exists only in the rat. The analysis of the genomic sequences of mouse and human PEP19 gene failed to reveal in these two organisms the fourth exon, present in the rat gene, that encodes the alternative $\mathrm{N}$-terminal portion of LPI. In the 
rat LPI form (ex1+ex $2+e x 3^{*}+e x 3$, Fig. 2), the start site for translation $\left(\mathrm{ATG}^{*}\right)$ is different, but the stop codon is the same as in the short form (ex1+ex2+ex3). Moreover, the 3'-ends of the two alternate spliced mRNAs maintain the same frame, so that PEP19 and LPI have common C-terminal ends, that contain the IQ motifs involved in calmodulin binding.

The large introns present in human, mouse and rat PCP4 genes may contain regulatory elements and/or unidentified exons. Exonisation of intronic sequences has been shown to be one of the evolution processes to create new exons (35). LPI cDNA highlights one of these exons observed only in the rat and corresponding to a rare transcript. We could not exclude that such a transcript exists in the mouse, but it should be rare as it is not found in databases and would not encode a similar LPI amino acid sequence. The sequence in the mouse homologous to the rat LPI exon is identical in C57BL/6J and 129 (129S6/SvEvTac) strain genomic sequences suggesting that it is specific for the mouse species. The comparison with the rat sequence identified an insertion/deletion separating the mouse from the rat sequences that may be observed as both species diverged 16 million years ago. These results also suggest that exonisation of PCP4 introns may exist in other species.

By using antibodies with different specificities, we found that LPI is particularly expressed in the first two weeks of postnatal development. In the adult rat, LPI is less abundant than PEP19 (like, on the other hand, its mRNA) and its existence has been probably hidden in the past by the abundance of PEP19 itself. The discrepancy in the developmental profiles of the $10-\mathrm{kDa}$ protein, noticed by using an LPI-specific ('anti-LPI N-end') antibody, in comparison with anti-LPI/PEP19 sera, suggests that the 10-kDa species, evidenced with anti-LPI/PEP19 antibodies, is made up of at least two different proteins: LPI (produced earlier during brain development and less represented in the adult brain) and some post-translationally modified form of PEP19 itself (that should be the main form present in the adult brain). Very recently, it has been suggested that PEP19 can undergo phosphorylation at a serine in the IQ motif (36) and PEP19 function could be regulated through this and possibly other post-translational modifications, some of which might affect its electrophoretic migration.

The fact that LPI is expressed only in the rat suggests that it might play a specific adaptative role in the first phases of brain maturation, a role that might be played by other proteins in mice and humans. It is worth noting that LPI is present also in the nuclear extracts, where it remains at higher concentration than in the cytoplasm also in the adult brain, thus suggesting a nuclear-specific function. In the course of our study, we were able to demonstrate that PEP19 itself is present in the nucleus, again suggesting a nuclear-specific function, that might be either related or not with its calmodulin-binding ability and that could be modulated by post-translational modifications as well.

\section{Acknowledgements}

We are grateful to Dr J.I. Morgan for the gift of the PEP19 antiserum. This work was supported by the Italian Ministero dell'Università e della Ricerca (MIUR) and by the University of
Palermo (fondi di Ateneo, Università degli Studi di Palermo), Italy.

\section{References}

1. Berridge MJ, Bootman MD and Roderick HL: Calcium signalling: dynamics, homeostasis and remodelling. Nature Rev 4: 517-529, 2003.

2. Stull JT, Nunnally MH and Michnoff CH: Calmodulin-dependent protein kinases. In: The Enzymes, Vol 17, Control by Phosphorylation. Boyer PD and Krebs EG (eds). Academic, New York, pp113-166, 1986.

3. Cohen PTW: Novel protein serine/threonine phosphatases: variety is the spice of life. Trends Biol Sci 22: 245-251, 1997.

4. Harris AS, Croall DE and Morrow JS: Calmodulin regulates fodrin susceptibility to cleavage by calcium-dependent protease I. J Biol Chem 264: 17401-17408, 1989.

5. Bähler M and Rhoads A: Calmodulin signaling via the IQ motif. FEBS Lett 513: 107-113, 2002.

6. Alexander KA, Wakim BT, Doyle GS, Walsh KA and Storm DR: Identification and characterization of the calmodulin-binding domain of neuromodulin, a neurospecific calmodulin-binding protein. J Biol Chem 263: 7544-7549, 1988.

7. Baudie J, Deloulme JC, Van Dorsselaer A, Black D and Matthes HWD: Purification and characterization of a brainspecific protein kinase $\mathrm{C}$ substrate, neurogranin (p17). Identification of a consensus amino acid sequence between neurogranin and neuromodulin (GAP43) that corresponds to the protein kinase $\mathrm{C}$ phosphorylation site and the calmodulin-binding domain. J Biol Chem 266: 229-237, 1991.

8. Jurado LA, Chockalingam PS and Jarrett HW: Apocalmodulin. Physiol Rev 79: 661-682, 1999.

9. Choi DW: Glutamate neurotoxicity and diseases of the nervous system. Neuron 1: 623-634, 1988.

10. Trump BF and Berezesky IK: The role of cytosolic $\mathrm{Ca} 2^{+}$in cell injury, necrosis and apoptosis. Curr Opin Cell Biol 4: 227-232, 1992 .

11. Slemmon JR, Morgan JI, Fullerton SM, Danho W, Hilbush BS and Wengenack TM: Camstatins are peptide antagonists of calmodulin based upon a conserved structural motif in PEP19, neurogranin, and neuromodulin. J Biol Chem 271: 15911-15917, 1996.

12. Skene JH: Axonal growth-associated proteins. Annu Rev Neurosci 12: 127-156, 1989.

13. Baudier J, Bronner C, Kligman D and Cole RD: Protein kinase $\mathrm{C}$ substrates from bovine brain. Purification and characterization of neuromodulin, a neuron-specific calmodulin-binding protein. J Biol Chem 264: 1824-1828, 1989.

14. Liu Y and Storm DR: Regulation of free calmodulin levels by neuromodulin: neuron growth and regeneration. Trends Pharmacol Sci 11: 107-111, 1990.

15. Coggins PJ and Zwiers H: B-50 (GAP-43): biochemistry and functional neurochemistry of a neuron-specific phosphoprotein. J Neurochem 56: 1095-1106, 1991.

16. Watson JB, Margulies JE, Coulter PM 2nd, Gerendasy DD, Sutcliffe JG and Cohen RW: Functional studies of single-site variants in the calmodulin-binding domain of RC3/neurogranin in Xenopus oocytes. Neurosci Lett 219: 183-186, 1996.

17. Gerendasy DD and Sutcliffe JG: RC3/neurogranin, a postsynaptic calpacitin for setting the response threshold to calcium influxes. Mol Neurobiol 15: 131-163, 1997.

18. Ziai R, Pan YCE, Hulmes JD, Sangameswaran L and Morgan JI: Isolation, sequence, and developmental profile of a brain-specific polypeptide, PEP19. Proc Natl Acad Sci USA 83: 8420-8423, 1986.

19. Johanson RA, Sarau HM, Foley JJ and Slemmon JR: Calmodulinbinding peptide PEP19 modulates activation of calmodulin kinase II in situ. J Neurosci 20: 2860-2866, 2000.

20. Utal AK, Stopka AL, Roy M and Coleman PD: PEP19 immunohistochemistry defines the basal ganglia and associated structures in the adult human brain, and is dramatically reduced in Huntington's disease. Neuroscience 86: 1055-1063, 1998.

21. Erhardt JA, Legos JJ, Johanson RA, Slemmon JR and Wang X: Expression of PEP19 inhibits apoptosis in PC12 cells. Neuroreport 11: 3719-3723, 2000.

22. Castiglia D, Scaturro M, Nastasi T, Cestelli A and Di Liegro I: PIPPin, a putative RNA-binding protein specifically expressed in the rat brain. Biochem Biophys Res Commun 218: 390-394, 1996. 
23. Castiglia D, Gristina R, Scaturro $M$ and Di Liegro I: Cloning and analysis of cDNA for rat Histone $\mathrm{H} 1^{\circ}$. Nucleic Acids Res 21: 1674-1674, 1993.

24. Chomczynski P and Sacchi N: Single-step method of RNA isolation by acid guanidinium thiocyanate-phenol-chloroform extraction. Anal Biochem 162: 156-159, 1987.

25. Dignam JD, Lebovitz RM and Roeder RG: Accurate transcription initiation by RNA polymerase II in a soluble extract from isolated mammalian nuclei. Nucleic Acids Res 11: 1475-1489, 1983.

26. Bradford MM: A rapid and sensitive method for the quantitation of microgram quantities of protein utilizing the principle of protein dye binding. Anal Biochem 72: 248-254, 1976.

27. Savettieri G, Mazzola GA, Rodriguez-Sanchez MB, Caruso G, Di Liegro I and Cestelli A: Modulation of synapsin I gene expression in rat cortical neurons by extracellular matrix. Cell Mol Neurobiol 18: 369-378, 1998.

28. Ziai MR, Sangameswaran L, Hempstead JL, Danho W and Morgan JI: An immunochemical analysis of the distribution of a brain-specific polypeptide, PEP-19. J Neurochem 51: 1771-1776, 1988.

29. Nastasi T, Scaturro M, Bellafiore M, Raimondi L, Beccari S, Cestelli A and Di Liegro I: PIPPin is a brain-specific protein that contains a cold-shock domain and binds specifically to $\mathrm{H} 1^{\circ}$ and H3.3 mRNAs. J Biol Chem 274: 24087-24093, 1999.

30. Altschul SF, Madden TL, Schaffer AA, Zhang J, Zhang Z, Miller W and Lipman DJ: Gapped BLAST and PSI-BLAST: a new generation of protein database search programs. Nucleic Acids Res 25: 3389-3402, 1997.
31.Tatusova TA and Madden TL: BLAST 2 Sequences, a new tool for comparing protein and nucleotide sequences. FEMS Microbiol Lett 174: 247-250. Erratum in: FEMS Microbiol Lett 177: 187-188, 1999.

32. Higgins D, Thompson J, Gibson T, Thompson JD, Higgins DG and Gibson TJ: CLUSTAL W: improving the sensitivity of progressive multiple sequence alignment through sequence weighting, position-specific gap penalties and weight matrix choice. Nucleic Acids Res 22: 4673-4680, 1994.

33. Reese MG, Eeckman FH, Kulp D and Haussler D: Improved splice site detection in genie. J Comput Biol 4: 311-323, 1997.

34. Sangameswaran L, Hempstead J and Morgan JI: Molecular cloning of a neuron-specific transcript and its regulation during normal and aberrant cerebellar development. Proc Natl Acad Sci USA 86: 5651-5655, 1989.

35. Wang W, Zheng H, Yang S, Yu H, Li J, Jiang H, Su J, Yang L, Zhang J, McDermott J, Samudrala R, Wang J, Yang H, Yu J, Kristiansen K, Wong GK and Wang J: Origin and evolution of new exons in rodents. Genome Res 15: 1258-1264, 2005.

36. Dickerson JB, Morgan MA, Mishra A, Slaughter CA, Morgan JI and Zheng J: The influence of phosphorylation on the activity and structure of the neuronal IQ motif protein, PEP-19. Brain Res 1092: 16-27, 2006. 